\title{
RANCANGAN MODEL BISNIS SABUN CUCI RAMAH LINGKUNGAN
}

\section{BUSINESS MODEL OF DISH SOAP ECOFRIENDLY}

\author{
Indah Setiawati $^{1}$, Bambang Soemanto ${ }^{1}$, Yudi Syahrullah ${ }^{2}$, Indah Widyarini ${ }^{1}$ \\ ${ }^{1}$ Fakultas Pertanian, Universitas Jenderal Soedirman \\ ${ }^{2}$ Fakultas Teknik, Universitas Jenderal Soedirman \\ Email: iindahs@unsoed.ac.id \\ (Diterima 28-11-2021; Disetujui 22-01-2022)
}

\begin{abstract}
ABSTRAK
Jelantah merupakan minyak nabati yang dapat diolah menjadi produk sabun cuci. Peluang bisnis sabun cuci berbasis jelantah yang ramah lingkungan perlu dilakukan penelitian. Penelitian ini bertujuan untuk membuat rancangan bisnis sabun cuci ramah lingkungan menggunakan metode business model canvas (BMC). Sumber data didapatkan dari hasil wawancara mendalam dengan produsen sabun skala rumah tangga Inti Herba. Berdasarkan hasil analisis, terdapat 9 blok yang digunakan dalam merancang bisnis sabun cuci ramah lingkungan berbasis jelantah. Produk ramah lingkungan memiliki value proporsition menjadi produk hijau yang merupakan produk yang diminati oleh para pegiat lingkungan/konsumen hijau. Oleh karena itu, dalam rancangan bisnis sabun cuci ramah lingkungan ini memiliki segmen pasar adalah ibu rumah tangga yang merupakan pegiat lingkungan. Tujuh blok lain yang dikaji menggunakan BMC menunjukkan aspek-aspek penting yang berkaitan dengan perancangan bisnsi sabun cuci ramah lingkungan dari jelantah.
\end{abstract}

Kata kunci: sabun cuci, produk hijau, ramah lingkungan, BMC

\section{ABSTRACT}

Waste cooking is a vegetable oil that can be processed into laundry soap products. Business opportunities based on waste cooking soap that are environmentally friendly need to be researched. This study aims to create an environmentally friendly laundry soap business design using the Business Model Canvas (BMC) method. Sources of data obtained from in-depth interviews with household scale soap producer Inti Herba. Based on the results of the analysis, there are 9 blocks used in designing an environmentally friendly laundry soap business based on waste cooking. Environmentally friendly products have a value proportion to green products which are products that are in demand by environmental activists/green consumers. Therefore, in this eco-friendly laundry soap business design, the market segment is housewives who are environmental activists. The other seven blocks studied using BMC show important aspects related to the design of an environmentally friendly laundry soap business from waste cooking.

Keywords: dish soap, green product, eco-friendly, $B M C$

\section{PENDAHULUAN}

Minyak jelantah merupakan limbah rumah tangga yang perlu ditangani. Menurut Badan Pengelolaan Lingkungan Hidup Daerah DKI Jakarta, hanya 3 persen badan air di DKI Jakarta yang memenuhi baku mutu air. Penyebabnya dipicu oleh pencemaran yang tinggi dari minyak jelantah yang dibuang ke saluran air (Yudo, 2018). Untuk mengatasi hal tersebut perlu adanya pengolahan minyak jelantah agar tidak mencemari 
lingkungan kembali. Salah satu usaha yang dapat dilakukan adalah dengan membuat sabun cuci piring dengan bahan dasar minyak jelantah sehingga memberikan nilai ekonomi yang memiliki potensi pasar yang besar.

Minyak goreng bekas yang dihasilkan oleh rumah tangga dapat diolah menjadi sabun baik dalam sediaan bentuk padat maupun cair. Pemanfaatan sabun dihasilkan dari proses hidrolisis minyak atau lemak menjadi asam lemak bebas dan gliserol yang dilanjutkan dengan proses saponifikasi menggunakan basa. Asam lemak yang berikatan dengan basa ini kemudian disebut sebagai sabun (Setiawati, et al, 2020). Untuk menjernihkan pengotor dari minyak jelantah, diperlukan metode yang bisa menghilangkan pengotor yang terdapat pada minyak jelantah. Adsorben yang banyak digunakan adalah zeolit.

Saat ini sudah beredar sabun cuci piring menggunakan charcoal sebagai zat aktif tambahan. Sama seperti charcoal, zeolit juga berfungsi untuk menambah daya bersih pada produk. Zeolit alam memiliki kemampuan absorbsi lebih baik dari charcoal karena struktur porinya yang lebih tinggi. Zeolit alam juga memiliki kemampuan lebih baik dalam menurunkan kandungan logam berat
(Arryanto et al, 2012). Zeolit mampu mengurangi lebih banyak akan kadar logam kromium dan timbal pada limbah industri (Fahmi et al, 2019). Oleh karena itu, produk sabun cuci piring dari limbah jelantah yang dimurnikan menggunakan zeolit berpotensi sebagai bahan aktif tambahan merupakan inovasi yang perlu dikembangkan mengingat bahan baku zeolit alam yang melimpah di Indonesia.

Dalam mengembangkan bisnis, perlu dilakukan sebuah analisis model bisnis. Model bisnis memberikan gambaran menyeluruh antara sumberdaya yang dimiliki perusahaan dengan keunggulan produk yang ditampilkan (Pratama dan Azis, 2018). Model bisnis pada suatu usaha perlu dievaluasi perusahaan untuk memperdalam pengetahuan tentang komponen dasar sebuah usaha sehingga dapat menampilkan usaha dengan keunggulan bersaingnya di pasar (Gondosaputro, 2017). Model bisnis membantu merencakan dan mengambil keputusan dalam bisnis. Osterwalder dan Pigneur (2012) mengungkapkan bahwa model bisnis dapat dijelaskan dalam sembilan blok yang menampilkan kerangka berfikir tentang bagaimana perusahaan menghasilkan uang melalui produk/jasa yang ditampilkan. Sembilan blok tersebut 
meliputi proporsi nilai, hubungan dengan pelanggan, saluran, segmen konsumen, aliran pemasukan, komponen biaya, aktivitas kunci, partner kunci, dan sumber daya utama. Penelitian bertujuan untuk mengetahui bagaimana rancangan bisnis sabun cuci ramah lingkungan dari jelantah menggunakan analisis Business Model Canvas/BMC.

\section{METODE PENELITIAN}

Penelitian dilaksanakan di Kabupaten Brebes, Provinsi Jawa Tengah yang merupakan lokasi perusahaan sabun cuci ramah lingkungan Inti Herba. Perusahaan Inti Herba secara purposif dipilih sebagai lokasi penelitian karena merupakan salah satu inventor di Kabupaten Brebes yang fokus pada produk kimia ramah lingkungan. Penelitian dilakukan pada bulan JuniSeptember 2021.

Data yang digunakan meliputi data primer dan sekunder. Data primer didapatkan dari kegiatan wawancara secara mendalam (indepth interview) pada empat narasumber dari perusahaan Inti Herba yang meliputi pemilik usaha, bagian produksi, bagian pemasaran dan bagian pengembangan. Metode penelitian ini menggunakan metode kualitatif deskriptif yang bersifat induktif. Teknik pengumpulan data menggunakan observasi, wawancara, dan dokumentasi yang ditujukan kepada informan, serta data sekunder.

Analisis dilakukan dengan melakukan identifikasi terhadap kesembilan blok BMC yaitu Customer Segments (CS), Value Propositions (VP), Channels (CH), Customer Relationships (CR), Revenue Streams (RS), Key Resources (KR), Key Activities (KA), Key Partnerships (KP), dan Cost Structures (CS) diperlukan untuk mengetahui sasaran yang ingin dicapai perusahaan. Informan dari bagian produksi memberikan data yang berkaitan dengan blok VP, KR, KA, dan CS. Informan dari bagian pemasaran memberikan data yang berkaitan dengan blok CS, VP, CH, dan CR. Informan dari bagian pengembangan memberikan data yang berkaitan dengan blok VP, KA, dan RS. Informan dari pemilik perusahaan memberikan data secara keseluruhan setelah dilakukan wawancara mendalam pada tiga informan lainnya.

\section{HASIL DAN PEMBAHASAN}

Business Model Canvas pada Usaha Sabun Cuci Ramah Lingkungan

Berdasarkan wawancara secara mendalam kepada keempat informan di 
perusahaan Inti Herba didapatkan unsurunsur pembentuk model bisnis yang digambarkan dalam sembilan blok berikut.

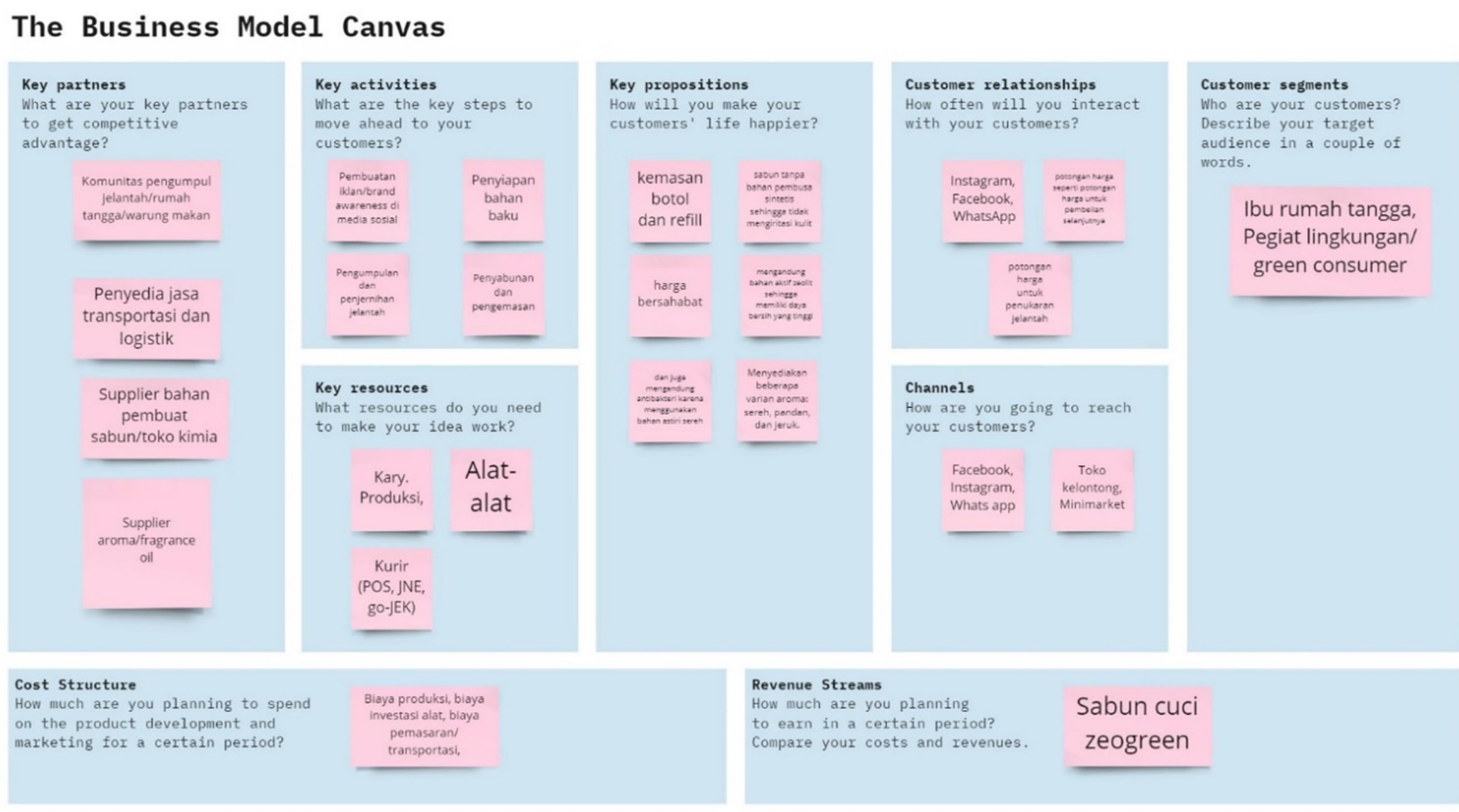

Sumber: Data Primer, 2021

Gambar 1. Business Model Canvas Sabun Cuci Ramah Lingkungan

\section{Customer Segments (CS)}

Produk sabun cuci ramah lingkungan merupakan produk dengan segmen khusus yakni para penggiat lingkungan. Berdasarkan segmentasi demografis, konsumen target adalah wanita/ibu rumah tangga, usia 20 tahun ke atas, bertempat tinggal di kota. Pemilihan segmentasi gender wanita karena produk berkaitan dengan produk perlengkapan rumah tangga yang umumnya menjadi tempat yang diakses oleh wanita (dapur). Usia 20 tahun ke atas selaras dengan pendapat bahwa di usia tersebut konsumen sudah memiliki daya beli (Setiawati, et al, 2020). Segmentasi berdasarkan perilaku digunakan untuk menunjukkan fokus pelanggan yang akan menjadi target pasar. Wanita usia 20 tahun merupakan segmen secara demografi. Segmentasi dilanjutkan pada segmentasi psikologi yakni pelanggan sabun cuci lembut di kulit yang disebabkan oleh faktor iritan. wanita yang memiliki kulit sensitif akan mencari alternatif sabun yang bebas surfaktan sintetis. Segmentasi berdasarkan perilaku adalah wanita/ibu 
rumah tangga yang memiliki perhatian pada keberlanjutan lingkungan. Penjualan sabun cuci diharapkan akan diarahkan pada komunitas pegiat lingkungan yang ada di perkotaan dan sekitarnya.

\section{Value Propositions (VP)}

Nilai keunggulan dari produk sabun cuci yang dikembangkan adalah produk sabun tanpa bahan pembusa kimia sintetis sehingga tidak mengiritasi kulit, harga bersaing yakni Rp10.000,00 per kemasan botol isi $500 \mathrm{~mL}$, mengandung bahan aktif zeolit sehingga memiliki daya bersih yang tinggi, dan juga mengandung antibakteri karena menggunakan bahan astiri sereh. Menurut Setiawati et al (2020), atribut mutu sabun yang penting bagi konsumen adalah bebas SLS, tidak mengiritasi kulit dan memiliki daya bersih yang maksimal. Atribut daya bersih merupakan mutu yang paling utama pada produk pembersih seperti sabun.

\section{Channels $(\mathrm{CH})$}

Saluran yang digunakan untuk mengantarkan produk kepada konsumen diantaranya toko kelontong dengan sistem pembayaran konsinyasi, penjualan langsung melalui display/toko di rumah produksi dan juga dapat dilakukan melalui media sosial seperti whatsapp business, instagram dan facebook.
Saluran tersebut dipilih karena perusahaan saat ini masih membangun brand dengan jangkauan pemasaran yang sedikit (business to consumer/B2C). Komunikasi, distribusi dan jalur penjualan memberikan perusahaan suatu anjak muka bagi perusahaan kepada para pelanggannya (Warnaningtyas, 2020).

\section{Customer Relationships (CR)}

Blok ini menjelaskan bagaimana perusahaan membangun hubungan dengan segmen pelanggan yang akan dicapainya (Gondosaputro, 2017). Jenis hubungan pada masing-masing segmen konsumen ditentukan oleh perusahaan agar proses akuisisi, retensi dan loyalitas terbentuk. Hubungan diterapkan secara pendekatan personal dengan membangun brand awareness berupa motivasi untuk memperoleh produk ramah lingkungan, mempertahankan pelanggan dan meningkatkan penjualan. Adapun customer relationship pada perusahaan sabun cuci ramah lingkungan yaitu admin sosial media/customer service yang selama ini sudah dilakukan oleh pemilik usaha dan staf bidang pemasarannya.

\section{Revenue Streams (RS)}

Pemasukan utama perusahaan adalah dengan menjual produk sabun cuci ramah lingkungan kemasan botol. Target penjualan per bulan adalah 300 botol dan 
saat ini di tahun pertama sudah mencapai target tersebut.

\section{Key Resources (KR)}

Sumberdaya utama pada usaha sabun cuci ramah lingkungan perlu dianalisis sebagai kekuatan internal perusahaan untuk mengembangkan usaha dan eksistensinya dalam menghadapi pasar. Sumberdaya utama pada usaha sabun cuci ramah lingkungan meliputi bahan baku, perlengkapan/alat-alat produksi, tenaga kerja, dan manajemen.

\section{Key Activities (KA)}

Sabun cuci ramah lingkungan berkaitan dengan aktivitas produksi, aktivitas pemasaran, dan aktivitas persediaan bahan. Aktivitas produksi berkaitan dengan aktivitas penyediaan bahan karena sebelum kegiatan produksi, perusahaan harus sudah membangun aktivitas penyediaan bahan baku minyak limbah jelantahnya untuk kemudian diolah menjadi sabun cuci. Aktivitas ini dilakukan dengan membuat kerjasama dengan rumah makan atau komunitas rumah tangga yang memiliki giat pada lingkungan sehingga mereka mau memberikan jelantah sisa masak kepada perusahaan Inti Herba. Aktivitas pemasaran dilakukan meliputi kegiatan kerjasama dengan toko kelontong dan media partner dalam pemasaran terutama media online

\section{Key Partnerships (KP)}

Usaha tak akan mampu berdiri sendiri dalam memenuhi kebutuhan konsumen dan menghadapi persaingan di pasar. Pihak-pihak yang terkait dalam mendukung eksistensi bisnis sabun cuci ramah lingkungan meliputi rumah tangga/rumah makan penyedia bahan baku minyak jelantah, toko kimia penyedia bahan baku utama dan bahan pendukung, penyedia bahan pengaroma seperti petani penghasil atsiri sereh dari Kabupaten Brebes, penyedia jasa kurir dan logistik seperti berlangganan pada kurir yang menyediakan jemput paket secara gratis.

\section{Cost Structures (CS)}

Struktur biaya dalam usaha sabun cuci ramah lingkungan meliputi biaya tetap dan biaya variabel. Biaya tetap meliputi biaya perlengkapan dan alat produksi seperti alat reaktor saponifikasi, alat pengadukan dan alat pelabelan. Biaya variabel merupakan biaya yang berkaitan dengan proses produksi seperti bahan baku utama, bahan baku pendukung, bahan baku penolong, biaya tenaga kerja buruh harian. Biaya lain yang meliputi biaya pemasaran dan transportasi juga merupakan biaya yang 
dikeluarkan perusahaan namun prosentasenya lebih sedikit dari biaya produksi dan biaya perlengkapan.

\section{Analisis SWOT}

Analisis SWOT dilakukan untuk mengetahui kekuatan dan kelemahan pada internal perusahaan dan mengetahui peluang dan ancaman yang dihadapi perusahaan dalam memasuki pasar. Analisis SWOT telah dilakukan melalui wawancara mendalam kepada pemilik usaha Inti Herba. Perusahaan telah berdiri sejak tahun 2017 dengan mengembangkan produk berbasis herbal/ramah lingkungan. Selama terjun ke pasar, Inti Herba mengalami beberapa kondisi eksternal yang berupa ancaman dan peluang. Ancaman yang dihadapi selama menjalani usaha dan yang mungkin akan dihadapi di waktu mendatang diantaranya adalah pesaing sabun cuci curah yang harganya sangat murah. Pesaing sabun curah menjual harga ecer per botol dengan isi yang sama yakni 500 Ml dijual dengan harga Rp5.000,00. Hal ini menjadi ancaman bagi usaha sabun cuci. Namun sabun tersebut memiliki mutu yang berbeda sehingga disinilah yang menjadi pekerjaan perusahaan untuk membangun brand dengan menyadarkan pada masyarakat tentang bahaya sabun cuci yang berbasis bahan kimia sintetis. Pengetahuan masyarakat Indonesia mengenai ecolabelling masih rendah, berbeda dengan masyarakat di negara maju yang memiliki pengetahuan ecolabelling tinggi (Susilo, 2016). Ancaman lain yang mungkin dihadapi perusahaan adalah peraturan mengenai izin usaha. Izin edar PKRT yang menjadi prasyarat usaha sabun cuci belum dimiliki perusahaan namun izin edar ini tidak terlalu besar dampaknya karena untuk izin edar PKRT tidak seketat izin edar BPOM.

Analisis SWOT dilanjutkan dengan mengetahui peluang. Peluang usaha sabun cuci terbesar adalah demand yang tinggi. Dengan menampilkan harga yang bersaing dengan produk bermerek terkenal namun berbasis pada bahan kimia sintetis dan rentan menimbulkan iritasi kulit, sabun cuci ramah lingkungan dari Inti Herba memiliki peluang besar untuk mengakuisisi pasar baru. Sabun cuci berbasis surfaktan dari tanaman sudah mulai ada di pasaran namun fungsional hanya untuk pakaian dan memiliki harga yang cukup tinggi.

Analisis SWOT yang berkaitan dengan kondisi internal perusahaan meliputi aspek kekuatan dan kelemahan. 
Usaha sabun cuci ramah lingkungan ini memiliki kekuatan pada keunggulan produk/value propositions yakni menampilkan produk bebas surfaktan sintetis, berbahan limbah minyak jelantah dan berbahan aktif zeolit sehingga memiliki daya bersih yang baik. Kekuatan lain yang dimiliki perusahaan adalah sumberdaya produksi yang memiliki keterampilan khusus dalam membuat sabun cuci dengan teknologi yang mudah dan murah. Pemilik usaha telah melakukan riset bagaimana menghasilkan sabun cuci dari minyak jelantah dengan hasil yang jernih sehingga menyerupai sabun cuci yang beredar di pasaran. Kekuatan modal usaha juga menjadi sumberdaya utama dalam menjalankan usaha. Dengan teknologi yang mudah dan murah, perusahaan hanya memerlukan modal awal sebesar Rp5.000.000,00 (lima juta rupiah).

Analisis SWOT yang berkaitan dengan kelemahan meliputi izin edar
PKRT yang belum dimiliki perusahaan, luas rumah produksi yang sempit yakni hanya ruangan berukuran $4 \times 3$ meter dengan sekat tidak permanen, dan kelemahan pada produk yang hanya menggunakan kemasan botol sehingga tidak menyediakan kemasan refill. Kemasan botol ini akan menyulitkan pengiriman berjumlah banyak sehingga belum bisa menerapkan model bisnis B2B (business to business).

Berdasarkan analisis SWOT, ditentukan strategi bisnis yang dapat diterapkan perusahaan. Strategi bisnis ini meliputi bagaiama kekuatan internal perusahaan dapat menghadapi ancaman yang terjadi, bagaimana kekuatan dapat mengambil peluang yang ada, bagaimana mengatasi kelemahan dan ancaman, serta bagaimana mengatasi kelemahan dalam mengambil peluang. Strategi usaha berdasarkan analisis SWOT disajikan pada Tabel 1.

Tabel 1. Strategi usaha berdasarkan analisis SWOT

\begin{tabular}{|l|l|l|}
\hline & Kekuatan & Kelemahan \\
\hline Ancaman & $\begin{array}{l}\text { Membangun brand awareness dan } \\
\text { meningkatkan efisiensi produksi agar dapat } \\
\text { bersaing di pasar. }\end{array}$ & $\begin{array}{l}\text { Mengurus izin edar PKRT di Kementerian } \\
\text { kesehatan dengan cara mendaftarkan diri } \\
\text { sebagai tenan pada inkubator bisnis. }\end{array}$ \\
\hline Peluang & $\begin{array}{l}\text { Meningkatkan kapasitas produksi dan } \\
\text { menambah varian kemasan agar produk dapat } \\
\text { menjangkau pasar yang lebih luas. }\end{array}$ & $\begin{array}{l}\text { Mengurus izin edar dan memperluas } \\
\text { pemasaran dengan menerapkan model bisnis } \\
\text { B2B. }\end{array}$ \\
\hline
\end{tabular}




\section{KESIMPULAN DAN SARAN}

\section{Kesimpulan}

Berdasarkan analisis menggunakan BMC dan SWOT, bisnis sabun cuci ramah lingkungan dengan menggunakan bahan baku utama minyak jelantah memiliki keunggulan produk yang unik, kreatif dan inovatif karena saat ini belum ada sabun cuci menggunakan bahan baku jelantah dengan bahan aktif zeolit dan antibakteri sereh. Usaha sabun cuci ramah lingkungan ini memiliki peluang usaha yang besar dan pangsa pasar yang luas dan akan terus meningkat. Mengembangkan model bisnis dengan tidak hanya berbasis $\mathrm{B} 2 \mathrm{C}$ namun juga B2B dapat menjadi strategi perusahaan di masa mendatang untuk menangkap demand yang lebih besar hingga ke pasar nasional.

\section{Saran}

Sebagai saran untuk keberlanjutan usaha, perusahaan harus meningkatkan manajemen usaha dengan mengikutsertakan perusahaan pada inkubator bisnis baik di daerah provinsi (Bappeda Jawa Tengah) maupun melalui inkubator perguruan tinggi terdekat di Jawa Tengah. Keikutsertaan ini akan sangat membantu perusahaan dalam mendapatkan pendampingan legalitas usaha dan izin edar.

\section{UCAPAN TERIMA KASIH}

Ucapan terima kasih diberikan kepada Lembaga Penelitian dan Pengabdian Masyarakat Universitas Jenderal Soedirman (LPPM UNSOED) yang telah mendanai penelitian ini dalam skema Riset Peningkatan Kompetensi BLU UNSOED.

\section{DAFTAR PUSTAKA}

Alamsyah, M. dan R. Kalla. 2017. Pemurnian minyak jelantah dengan proses adsorbsi. Journal of Chemical Process Engineering, 2 (1): 22-26.

Arryanto, Y., Suwardi, Husaini, T. Affandi, S. Amini, M.A. Jabri, P. Siagian, D. Setyorini, A. Rahman, dan Y. Pujiastuti. 2012. Zeolit dan Masa Depan Bangsa. Penerbit Imperium. Yogyakarta, Indonesia.

Badan Pusat Statistik Kabupaten Banyumas. 2006. Jumlah Penduduk Kabupaten Banyumas. Badan Pusat Statistik : Banyumas

Fahmi, M. A., E. Yuliani, dan T.B. Prayogo. 2019. Studi efisiensi filter penjernih air menggunakan kombinasi bahan batu scoria dan batu apung dengan zeolit dan kerikil untuk mengurangi polutan pada limbah sintetis ( $\mathrm{Cr}$ dan $\mathrm{Pb}$ ). Jurnal Mahasiswa Jurusan Teknik Pengairan, 2 (1): 56-65.

Gondosaputro, H. M. (2017). Analisis Business Model Canvas Pada CV. Triputra Perkasa. Agora, 5(1).

Pangaribuan, L. 2018. Efek samping kosmetik dan penangananya bagi 
kaum perempuan. Jurnal Keluarga Sehat Sejahtera, 15 (1): 20-28.

Pratama, R. P., \& Azis, E. (2018). Analisis model bisnis dengan pendekatan business model canvas (studi kasus MxD). eProceedings of Management, 5(3).

Setiawati, I., Ardiansyah, A., \& Dewi, E. M. (2020). Aplikasi Quality Function Deployment Dalam Perancangan Sabun Mandi Herbal Virgin Coconut Oil. Jurnal Teknik, 9(2).

Susilo, B. O. (2016). Pengetahuan Ecolabel Di Indonesia Versus Pengetahuan Ecolabel Di Negara Maju Yang Berpengaruh Pada Niat Dan Keputusan Pembelian.
Competence: Journal of Management Studies, 10(2).

Warnaningtyas, H. (2020). Desain Bisnis Model Canvas (BMC) Pada Usaha Batik Kota Madiun. JURNAL EKOMAKS: Jurnal Manajemen, Ekonomi Kreatif dan Bisnis, 9(2), 52-65.

Yudo, S. 2018. Kondisi kualitas air sungai ciliwung di wilayah DKI Jakarta ditinjau dari paramater organik, amoniak, fosfat, deterjen dan bakteri coli. Jurnal Air Indonesia. 6 (1): 21-35. 